K.P. Geigle, J. Zerbs, R. Hadef, C. Guin, Laser-induced incandescence for soot measurements in an aero-engine combustor at pressures up to 20 bar, Appl. Phys. B 125:96 (2019).

The original publication is available at www.springerlink.com

http://dx.doi.org/10.1007/s00340-019-7211-2/ 


\title{
Laser-induced incandescence for soot measurements in an aero-engine combustor at pressures up to 20 bar
}

\author{
K.P. Geigle ${ }^{1^{*}}$, J. Zerbs ${ }^{1}$, R. Hadef ${ }^{1,2}$, C. Guin ${ }^{3}$ \\ ${ }^{1}$ Institute of Combustion Technology, German Aerospace Center (DLR), \\ Pfaffenwaldring 38-40, 70569 Stuttgart, Germany \\ ${ }^{2}$ Institut de Génie Mécanique, Université Larbi Ben M'Hidi, Oum El Bouaghi, Algérie \\ ${ }^{3}$ Department of Multi-Physics for Energetics, ONERA, Palaiseau, France \\ * phone +49-711-6862-398, fax +49-711-6862-598, klauspeter.geigle@dlr.de
}

\begin{abstract}
Soot is one of the most discussed pollutants in ground and air traffic. Moreover, its effect as source of intense radiation is significant as soon as locally rich mixtures occur, especially at increased pressure. This motivates the need to better understand soot formation and oxidation in turbulent, pressurised environment in order to prevent its emission as much as possible. A detailed understanding of the underlying processes can be gained when correlating sophisticated CFD modelling with well-defined validation experiments at technical conditions. LII has proven to be a valuable diagnostic to quantitatively monitor soot distributions inside combustion processes. However, application to pressurized gas turbine combustors has rarely been published for several reasons. Here, we present trends for soot distributions inside at technical combustor operated between 4 and 20 bar at realistic geometries and flow rates. Considerations on tackling typical challenges at technical conditions are presented. The resulting time-averaged soot distributions serve to determine positions of soot formation and oxidation as well as quantification of soot concentrations under the highly challenging technical conditions of the study. In general, soot concentrations were found to be relatively low. In combination with data derived independently from the present work, involving application of other diagnostics $(\mathrm{OH}$ and kerosene distributions as well as temperatures), a good validation data set is available to support soot modellers.
\end{abstract}

\section{INTRODUCTION}

Soot emission from industrial combustors and engines has a major detrimental impact on air quality and human health, and is recognised as potential key factor in global warming. Moreover, its effect as source of intense radiation is significant as soon as local rich mixtures occur, especially at increased pressure. One of the high priorities of manufacturers in cooperation with research is to reduce the environmental impact of soot formation and improve the technology of these industrial combustors. In order to achieve that, a deeper understanding of the physical and chemical mechanisms governing soot formation and oxidation in flames is necessary. The success in modelling soot production in practical aero-engine combustors depends to a large extent on the correct description of mixing as stated in [1-3]. In the complex flow field prevailing in such combustors, the size and location of fuel-rich regions as sources of soot depend on fuel placement, vaporisation and mixing. A highly sensitive indicator of those fuel-rich regions is the spatially and temporally resolved distribution of the final product soot. Laser-based measuring techniques are found to be appropriate for quantification and characterization of in-flame particulates and emissions. Laser-induced incandescence (LII) in special is a technique that offers many advantages and unique capabilities for the characterisation of soot distributions in combustion [4, 5]. Recently, technologies have improved rapidly making technical combustion processes accessible for laser optical diagnostics. Applying laser-based methods to realistic combustors offers the opportunity to directly visualise those processes for improved understanding, and use of the experimental data for validation purposes, provided the boundary conditions are well defined. On the other hand, technical combustion conditions represent a real challenge to the application of laser diagnostics. Therefore, literature on LII imaging application under turbulent, pressurized conditions is sparse. Some publications exist with focus on automotive research (for example [6$10]$ ) and very few on stationary gas turbine-like combustion featuring turbulence, swirl and pressure [11-13], and detailed studies of soot formation in gas turbine combustors at high pressure have, to the authors knowledge, not yet been published. In this manuscript we report 
measurements that have been performed up to 20 bar inside a technical combustor operated with kerosene, and data acquisition as well as reduction and quantification are described in detail in the following sections. Finally, soot distributions for standardized ICAO (International Civil Aviation Organization) conditions and operating points exhibiting specific parameter variations are presented.

\section{EXPERIMENTAL SETUP}

\subsection{Test rig}

The test rig infrastructure at the ONERA Palaiseau M1 test facility provides a maximum air flow rate of $3 \mathrm{~kg} / \mathrm{s}$ at up to 30 bars. Air preheat is possible up to $850 \mathrm{~K}$. For the described experiments, a maximum pressure of 23 bar with $1.6 \mathrm{~kg} / \mathrm{s}$ air at $725 \mathrm{~K}$ preheat temperature were applied. Fuel staging (pilot and main) was provided by the fuel nozzle described below. Operating conditions covered the conditions idle, approach, cruise and "85\% ICAO" from the ICAO Landing and Take-off Cycle (LTO) as well as some others used for trend studies (Table 1).

Table 1: Operating conditions of the studied technical combustor; $\phi$ (pilot) is contained in $\phi$ (global); as evident, for idle the main injection is not employed.

\begin{tabular}{ccccc}
\hline Nomenclature & Pressure [bar] & T(air,in) [K] & $\phi$ (global) & $\phi$ (pilot) \\
\hline Idle, 7\% ICAO & 4 & 470 & 0.2 & 0.2 \\
\hline Approach, 30\% ICAO & 9.5 & 590 & 0.264 & 0.12 \\
\hline Cruise-Var1 & 16.5 & 590 & 0.36 & 0.065 \\
\hline Cruise-Var2 & 16.5 & 670 & 0.36 & 0.065 \\
\hline Cruise & 16.5 & 670 & 0.36 & 0.036 \\
\hline 85\% ICAO & 20 & 725 & 0.4 & 0.054 \\
\hline
\end{tabular}

\subsection{Combustion chamber}

The spray flame fed by the fuel injector is stabilised inside a combustion chamber which has a $105 \mathrm{~mm} \times 105 \mathrm{~mm}$ squared cross section and a length of $82 \mathrm{~mm}$ before converging to the combustor exit. As typical for swirl stabilised flames, the flame is relatively short due to the intense mixing provided by the swirl and exhibits an inner and an outer recirculation zone.

Large quartz windows are used, which withstand pressures up to 30 bars and typical flame temperatures. Their maintenance is provided by a strong film cooling: $26 \%$ of the total combustor air flushes the windows' inner surface. Laser sheets can be introduced through a $70 \mathrm{~mm} \times 30 \mathrm{~mm}$ window while two opposite windows of $70 \mathrm{~mm} \times 60 \mathrm{~mm}$ can be used for detection. With increasing heat release of the studied flames, typically beyond 10 bar, the combustor windows smoothly start to glow, but without exhibiting irreversible damages or interfering with the optical diagnostics. The required chamber pressure is generated by a movable water-cooled piston that is partially blocking the combustor exit.

\subsection{Injector}

In the studied technical fuel nozzle kerosene can be injected either axially (pilot) through an air blast nozzle or radially through circumferential fuel holes (main). Both fuel flows are separately controlled. While the two inner swirled air flows serve to atomise the pilot fuel (see Fig. 1) the main fuel is multi-point-injected directly into the outer swirled air flow. For a visual impression a picture at moderately sooting conditions is implemented into the schematic. 


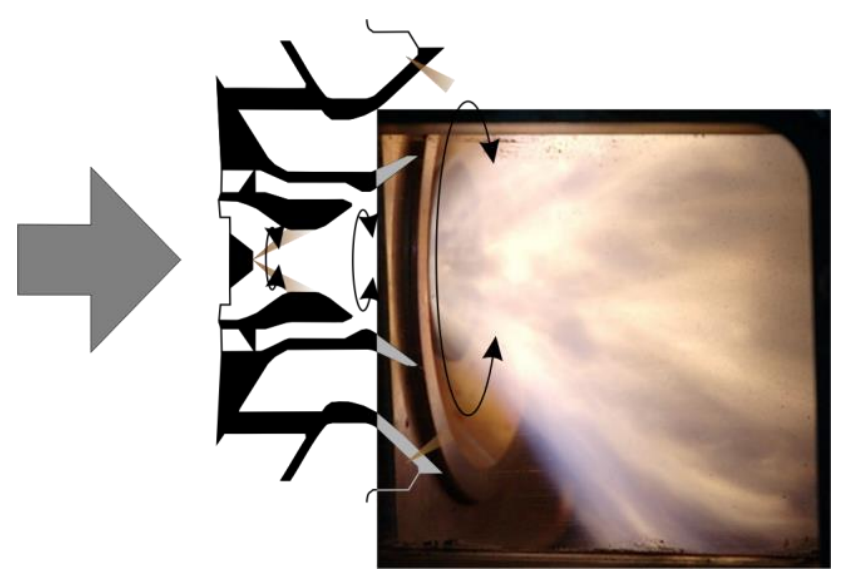

Fig. 1: Schematic of the fuel injector, including pilot (on the axis) and main (annular) and a picture at moderately rich conditions. Flow is from the left to the right.

\subsection{Laser-induced incandescence}

Laser-induced incandescence (LII) is based on heating the soot particles from flame temperatures up to the vaporisation temperature by a high-energy laser pulse. The absorbed energy is partially emitted as black body radiation with the intensity maximum shifted to the blue compared to the ambient flame emission. Above a threshold value in laser power the LII radiation intensity is approximately independent of the laser fluence. Since the particle size is expected to be distinctly smaller than the wavelength of the exciting light (Rayleigh regime) and approximately spherical primary particles are assumed, the recorded LII signal is directly proportional to the soot volume fraction. For quantification and determination of the calibration factor an independent measurement is necessary (typically an extinction experiment). A comprehensive discussion of the method and its applications can be found in $[4,5]$ and references therein.

\subsection{Optical setup}

The optical setup was distributed over two rooms due to safety issues and is illustrated in Fig. 2. The LIl-exciting Nd:YAG laser (Quantel, Brilliant) and diagnostics control were placed in a separate control room while the sheet forming optics as well as the detection devices were positioned close to the combustor. The $10 \mathrm{~Hz}$ laser output at $1064 \mathrm{~nm}$ was guided to an axis parallel to, and approximately $0.5 \mathrm{~m}$ above the burner axis with several mirrors. A folded 2-lens optics $\left(f_{\text {cyl }}=-80 \mathrm{~mm}, f_{\mathrm{sph}}=1000 \mathrm{~mm}\right.$ ) followed by an aperture distributed the laser pulse energy of $40 \mathrm{~mJ}$ to a sheet $34 \mathrm{~mm}$ high and $250 \mu \mathrm{m}$ wide. A final mirror deflected the sheet down into the combustor while the residual transmittance through this mirror was used to monitor the laser sheet quality on a beam profiler (Dataray, WinCamD). Due to the buoyant hot environmental air especially above the combustor, the laser sheet suffered some beam steering induced by thermal gradients. Yet, the sheet quality remained good enough for LII excitation. 


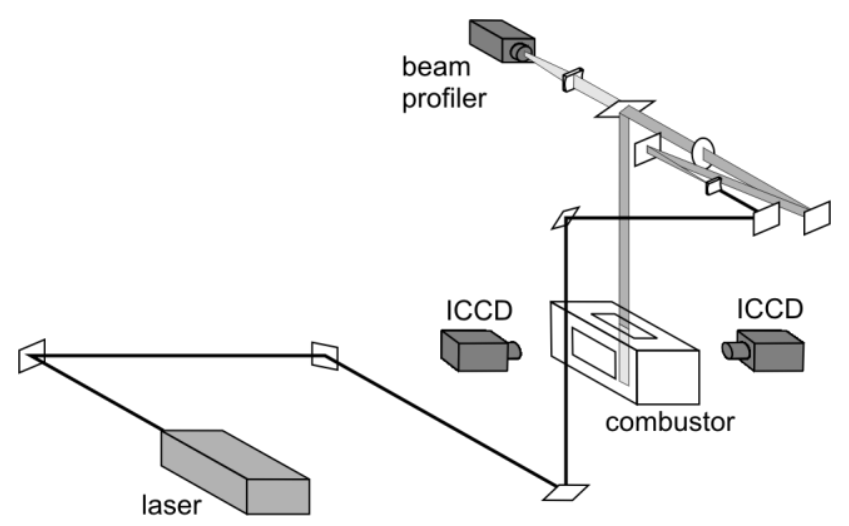

Fig. 2: Optical setup. Laser and combustor are separated by a safety wall.

A comparison of undisturbed and steered sheet (prior to entering the combustor) is displayed in Fig. 3. The laser fluence of $0.47 \mathrm{~J} / \mathrm{cm}^{2}$ varies by approximately $+/-25 \%$ within the sheet. According to Hofmann et al. [14], fluence curves do not change much with pressure. Thus, the choice of fluences well above reported typical threshold values for the plateau of the LII response curve under atmospheric conditions $\left(0.2 \mathrm{~J} / \mathrm{cm}^{2}\right.$ according to, for example, [15]), considering fluence variations within the sheet profile and from shot to shot appears reasonable. Our chosen value also accounts for deterioration of the laser sheet quality inside the combustor due to beam steering caused by strong thermal gradients, as recommended by Zerbs et al. [16].

Perpendicular to the LII excitation in a plane through the burner axis, one ICCD (Lavision, Flamestar 2) was employed to detect chemiluminescence of thermally excited $\mathrm{OH}$ radicals. It was equipped with an appropriate spectral filter around $315 \mathrm{~nm}$ and operated with a $20 \mu \mathrm{s}$ gate to monitor the reaction zone. Through the opposite window, a second ICCD (PCO, Dicam Pro) recorded soot luminosity and LII at $450 \mathrm{~nm}$ with $60 \mathrm{~ns}$ gates each. The camera's double frame option allows determining the flame background 500 ns before the laser pulse, i.e. at exactly the same flame conditions. In spite of being weak in intensity, the first frame contains valuable information about the line-of-sight soot distribution of the flame. Due to the combustor window dimensions and constraints of the ICCD locations, not the complete flame is imaged. Nevertheless, the full injector outlet plus some additional millimetres are visible on the images, covering a large and important region of the flame measuring roughly $66 \times 55 \mathrm{~mm}^{2}$. At every operating condition a sequence of 300 single laser shots was recorded with both cameras simultaneously. The fourth side of the combustor was equipped with an instrumentation flange.

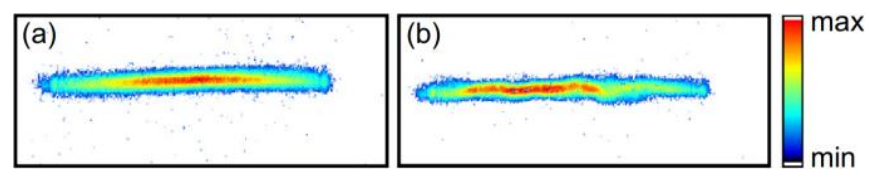

Fig. 3: Beam profile monitored before the laser sheet entering the combustor. (a) before combustor operation and (b) during operation.

In a second measurement campaign, the laser excitation plane was rotated by $90^{\circ}$ to image a plane parallel to the burner front panel. In this case a perpendicular detection is impossible. Thus, the camera was oriented relative to the excitation plane by a certain angle while the resulting distortion was corrected for in the data analysis. For this approach only planes close to the injector were accessible. Unlike with the first described geometry, the laser sheet could leave the combustor through a quartz window rather than hitting the formerly used instrumentation flange. 


\subsection{Quantification of laser-induced incandescence images}

The highly turbulent flame with its expectedly low soot content of high temporal and spatial fluctuations prohibited an in-situ online calibration with a simultaneous extinction experiment. A suitable stable calibration flame could not be introduced in the position of the measurement due to spatial constraints as for example described in $[6,7,17,18]$. Alternatively, a calibration experiment was performed ex-situ in the laboratory applying the same LII excitation and detection system in the same geometry with similarly thick combustion chamber windows to a stationary atmospheric premixed sooting calibration flame characterized in [16]. For the transfer of a LII calibration from ambient to increased pressure conditions, Vander Wal provides an excellent quotation, 'As LII is applied to practical combustion systems operating at pressure, semi-empirical calibration may be required with models supplying a pressure correction factor to calibrations performed at atmospheric pressure' [19]. Such model-based considerations have since been realized to some part: Kim et al. and Cenker et al. [20, 21] primarily focused on the decay behavior of the LII signal for particle sizing at increased pressure. Hofmann et al. validated experimentally that the proportionality of 50-ns gated LII intensity with soot volume fraction derived from extinction measurements holds for laminar flames at least up to 15 bar within some experimental scatter [14].

Hadef and Geigle in contrast use the particle size as proxy for soot volume fraction [22] and evaluate the integrated intensity within a hypothetical camera gate without normalization based on the LII model presented in [23], considering not only change of the decay rate with pressure but also the variation of absolute signal levels. The authors calculated the variation of gated LII intensity with increasing pressure for typical experimental boundary conditions (gas temperature of $1700 \mathrm{~K}$, measured spatial and temporal laser profile and detection filter curve as for the current experiment, $1064 \mathrm{~nm}$ excitation wavelength and a fluence of $0.4 \mathrm{~J} / \mathrm{cm}^{2}$ ). For acquisition times of $60 \mathrm{~ns}$, a given soot concentration represented as monodisperse $30-\mathrm{nm}$ primary particles is calculated to show a signal decrease of about $26 \%$ at 20 bar [22], see Fig. 4 . Inclusion of polydispersity, which is expected to prevail under the given technical conditions, as well as larger primary particles decrease this effect. Since the exact morphology of particles in the irradiated laser sheet is typically unknown, the same is valid for the variation of optical soot properties at high pressure and temperature, and LII models show some uncertainty for fluences in the LII plateau regime where sublimation is present, such extrapolation of the LII signal behavior from ambient to increased pressure can only be a rough guidance; yet, the induced bias towards too low soot concentrations is moderate and not included in the data evaluation.

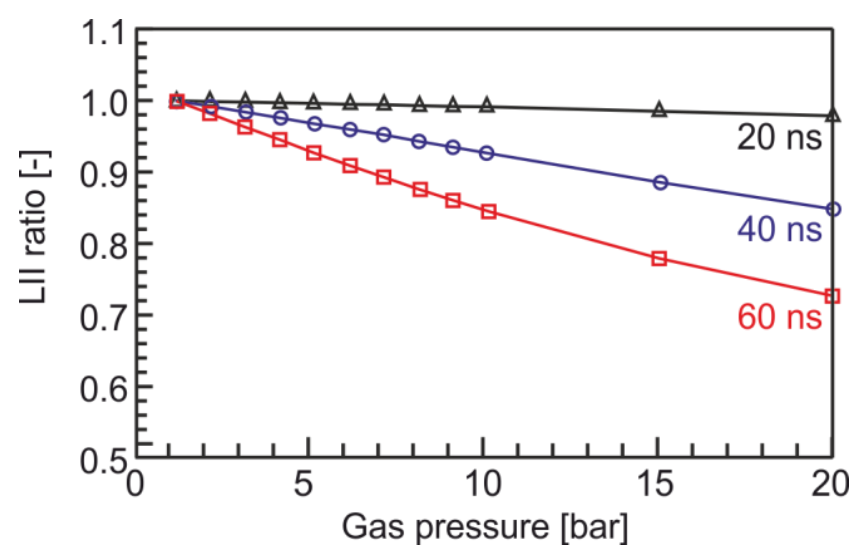

Fig. 4: Ratio of gated LII signal relative to that at ambient pressure for a 30 -nm primary particle and the conditions described in the text. 


\subsection{Detection interferences}

Spray scattering interferences of the exciting laser into the LII detection window were not to be expected $[8,17]$ due to the difference in excitation and detection wavelengths. Another interference turned out to be more severe. Opposite of the combustor window serving to introduce the laser sheet, an instrumentation flange was mounted. Sufficiently close to the laser focus, white plasma was generated on the metal surface that was scattered into the LII camera by various combustion chamber and window flange surfaces. Due to its broadband and relatively long character, a temporal or spectral discrimination was not successful, and significant background is visible in the average of raw images (Fig. 5a). Instead, a suitable filtering mechanism had to be implemented into the data analysis procedure, removing large parts of this interference. The filtering routine is based on the completely different behaviour of scattered plasma light and LII events: while the plasma is generated more or less in the same position every laser shot, only depending on the sheet quality transmitted through the highly turbulent flow, the typically stronger LII events change position and intensity. As a result, blurred, low-intensity plasma scattering remains negligible in the single shot images that are dominated by intermittent LII events, if any. In rare cases of too high plasma scattering levels, the filtering routine failed though.
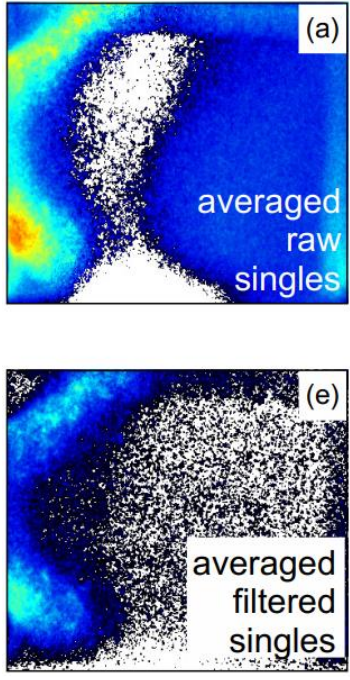
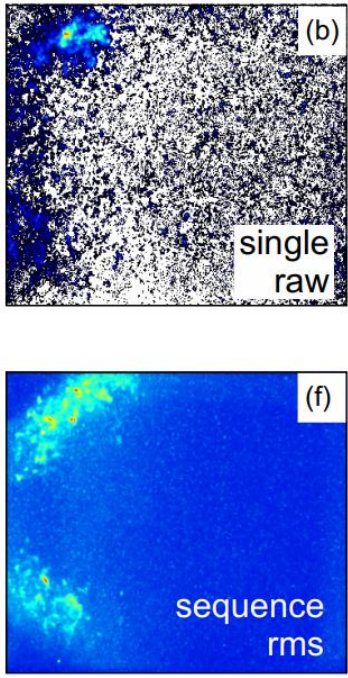
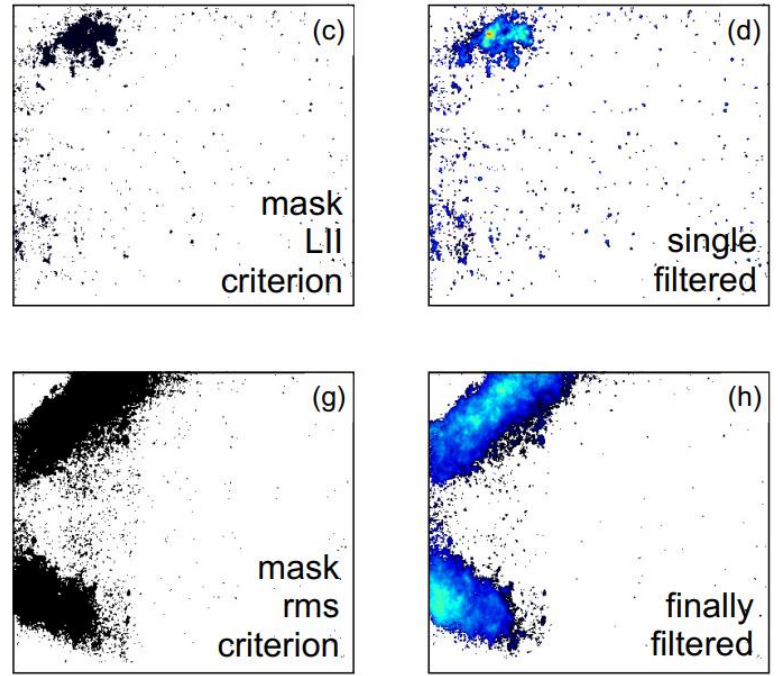

Fig. 5: Procedure of correcting time-averaged LII images for scattered plasma light; details are explained in the text. The plots in this and the subsequent figures have a dimension of roughly $66 \times 55 \mathrm{~mm}^{2}$ flush with the burner plate.

For the derivation of time-averaged images, two different masks were applied, as illustrated in Fig. 5: An average of raw instantaneous images is shown in Fig. 5a. It features a V-shaped soot cone on the left and relatively homogeneous, slightly increased intensity levels to the right. From the instantaneous images it is evident that the latter is primarily generated by increased background levels, but not by distinct soot filaments. A spatial mask on the instantaneous images (intensity thresholding) removes signal from areas of low, homogeneously distributed scattering as well as background noise without significant spatial dynamics (Fig. 5b-5d, application of 'mask LII').

High dynamics of the LII events, combined with typical, high soot intermittency are expressed as high values in the rms image of a sequence of 300 instantaneous images. Here, plasma scattering is characterised by moderate values and low spatial variation, in contrast to LII events. The rms image is therefore used as a secondary filter (again intensity thresholding), removing intensity from positions where too low intensity fluctuations occur (Fig. 5e-5h, application of 'mask rms'). The fact that the described interference was most prominent at lower pressure and insignificant at high pressure is most likely due to increasing beam steering which tends to diffuse the laser sheet upon passage through the combustor at high pressures. This correlates with the beam steering study reported in [16], and adds to the uncertainty of the measurement location and 
of the local fluence in the measurement location. If the variation of local fluence should be significantly stronger than in [16], the apparent soot volume fraction for the high pressure conditions would accordingly be lower than the real values.

\section{RESULTS}

In all following representations, flames burn from left to right. Fig. 6 illustrates the advantage of laser-excited emission diagnostics as the central image (b), laser-induced incandescence, represents the time-averaged soot distribution in the plane of laser excitation. In contrast to the line-of-sight diagnostics without laser excitation, namely $\mathrm{OH}$ chemiluminescence (a) and soot emission (c), it can be quantified as displayed below, and describes the soot distribution in the excitation plane. Both line-of-sight images at this operating condition (cruise) show a certain asymmetry of the flame, as frequently detected in swirl flames that are sensitive to various influence parameters of a combustor, for example buoyancy or partial flow blockages in the plenum due to the fuel arm. The asymmetry of the soot distribution in the LII image is therefore not a consequence of laser absorption along the laser sheet path, but rather a real feature of the studied flame. While the $\mathrm{OH}^{*}$ image shows a more diffuse species distribution, the soot emission is rather localised and fits well to the spatially resolved LII distribution. Concentrations of both species drop to very low values within the monitored area, even faster in the case of soot, that is oxidised to values below the sensitivity of the detection device. The short flame length represented by both species correlates well with the visual impression and expectations for a swirl flame.

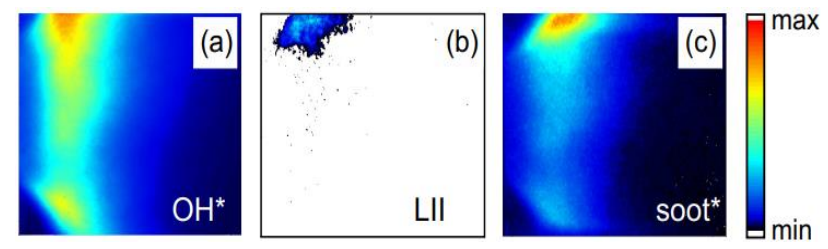

Fig. 6: Qualitative correlation of laser-induced and passive diagnostics at cruise condition: LII (b), $\mathrm{OH}$ chemiluminescence (a), soot emission (c) all show asymmetrical flame behaviour.

In the next Fig. 7 the time-averaged soot distribution from cruise conditions (Fig. 6) is complemented by three other ICAO standard conditions: idle (a), approach (b) and "85\% ICAO" (d). The soot distribution is not in all cases comparably asymmetric as at cruise conditions. For the idle representation it must be noticed that strong combustor window pollution occurred during the measurements, mainly due to the low air temperature and smaller mass flows inducing worse mixing, and leaving the windows surfaces too cold for soot oxidation to occur. It should be noted that switching to non-sooting conditions prior to measuring the desired sooty operating point as done in $[11,13]$ is not a viable strategy for large scale combustors. Typical clean-window periods of 15-30 seconds for operating points that quickly build up soot deposits on the combustor windows are insufficient to thermalize those devices of relatively high thermal inertia. Unlike signal photons, those soot covers did not affect the laser transmission, as the high power density easily vaporizes soot deposits in the optical path of the laser. The introduced contour line in Fig. 7a represents the limit of soot luminosity dropping to zero; in the central part of the combustor window soot on the inner window surface prevented signal transmission, similarly visible in the $\mathrm{OH}^{*}$ image as detected through the opposite combustor window. This effect was not observed for the other displayed flames. All conditions presented in this figure exhibit very low and relatively similar averaged soot concentrations at ppb level. Note that, according to Fig. 4 the soot volume fraction levels are presumably increasingly biased towards too low values as pressure increases (by about $6 \%$ for idle, $14 \%$ for approach, $22 \%$ for cruise and the maximum of $26 \%$ for " $85 \%$ ICAO"). However, a bias of this magnitude - values might vary a bit upon variations in the LII model used - 
does not affect the validity of the statements below. Downstream soot concentrations drop below the sensitivity level of the detection system or disappear out of the optically accessible regions; the corresponding images excited in a second laser sheet position further downstream are not shown as signal is negligible there. With one respect, the idle condition differs from the others: the detected soot distribution is located relatively close to the combustor axis. In this condition, all fuel is injected through the axial pilot fuel lance. The other operating conditions are characterised by decreasing pilot injection flow rates to zero, which results in soot formation at larger radial position.
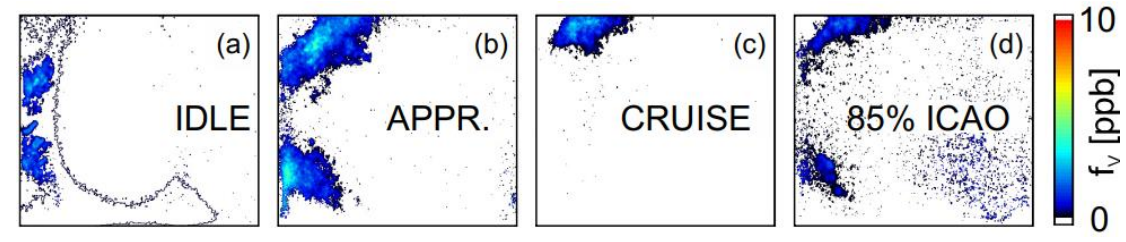

Fig. 7: Spatially resolved, time-averaged soot distributions for defined ICAO conditions.

The combustor's low soot formation propensity is also visible in Fig. 8. This figure shows several consecutive instantaneous images (color bar on the left) in comparison to the timeaveraged distribution on the right (with a separate color bar). Those instantaneous images are characterised by relatively small, mostly pointwise soot filaments with high temporal and spatial dynamics and variations. Several instantaneous images of a sequence do not show any LII signal. For strongly sooting flames, soot events are expected to be chained, wrinkled, linked, and finally surrounded by large homogeneous low-concentration soot fields. The dynamics and soot intermittency are reflected in the peak values up to $0.3 \mathrm{ppm}$, a still relative low value, while the average of 300 images is even below $10 \mathrm{ppb}$. Strongly sooting atmospheric turbulent jet flames burning the less-sooting ethylene in comparison have reported instantaneous peak soot volume fractions up to an order of 5-6 ppm [24, 25], and pressurized combustors using kerosene can have significantly higher soot levels $[1,12]$.
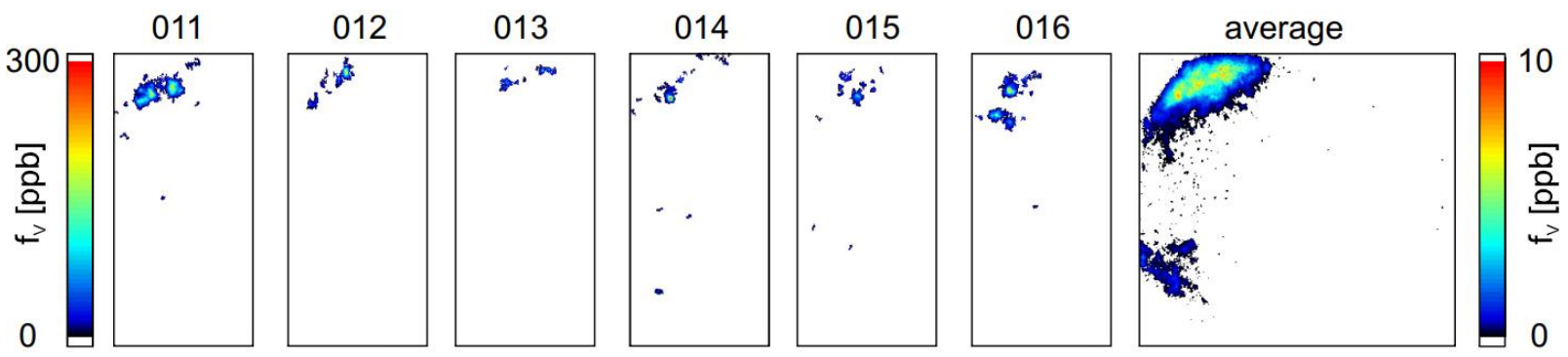

Fig. 8: Comparison of subsequent single shot soot distributions (color bar for quantification on the left) and time averaged soot distribution (color bar on the right) for combustor condition Var2.

Fig. 9 shows the trend of soot formation at different air inlet temperature for constant fuel injection, (a) and (b). In principle, soot formation should be kinetically controlled and thus augment at increased air inlet temperature in a certain flame temperature range. This behaviour is found for prevaporized kerosene combustion [26]. In contrast, this effect is counter-balanced in kerosene spray flames since increased temperature accelerates vaporisation of the spray followed by improved mixture and, consequently, reduction of locally rich conditions. 


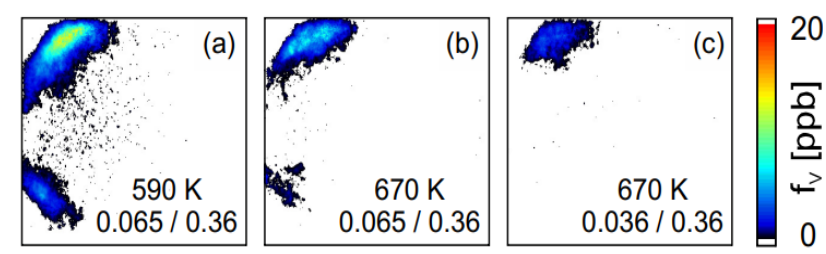

Fig. 9: Influence of air inlet temperature on soot formation, (a) and (b), Var1 and Var2, respectively, and fuel distribution at constant global $\phi$, (b) and (c); right is cruise. Note the different color bar relative to Fig. 8.

Shifting the fuel injection from pilot towards multi-hole main injection at constant global equivalence ratio, Fig. 9b) and (c), right is cruise, reduces soot production while soot formation occurs at larger distance from the nozzle. Distribution of the fuel through multi-holes rather than through the central pilot optimises the mixture under these operating conditions, resulting in reduced local fuel-rich spots and soot formation.

Regarding two planes parallel to the burner front panel at 4 and $13 \mathrm{~mm}$ distance, respectively, Fig. 10 indicates a circular, donut shaped soot field on average, increasing in diameter with distance from the burner as expected from the perpendicular view (Fig. 7). The horizontal shadows are due to starting cracks on the pressure windows or local window pollution preventing the laser from entering the combustor. Again, certain asymmetries are visible in the distributions, following the argumentation presented above. However, as already demonstrated above, soot concentrations increase with distance from the injector. Close to the burner axis and in the corner recirculation zones no soot is detected. The remaining fine-structure in these sequence-averaged images is due to the still statistically insufficient number of instantaneous images acquired per sequence. Origin of that is the high intermittency of soot formation in turbulent combustion relative to that of other species such as $\mathrm{OH}$. Therefore, the shown distributions are a good compromise between statistic evidence and limited and costly run times. In general, the cross sections shown in Fig. 10 provide a good complement to the soot distributions including the combustor axis (Figs. 79 ). Combined with other quantities $[27,28]$ the presented soot distributions represent a valuable data set for validation of numeric tools for prediction of soot formation in technical combustion [29].
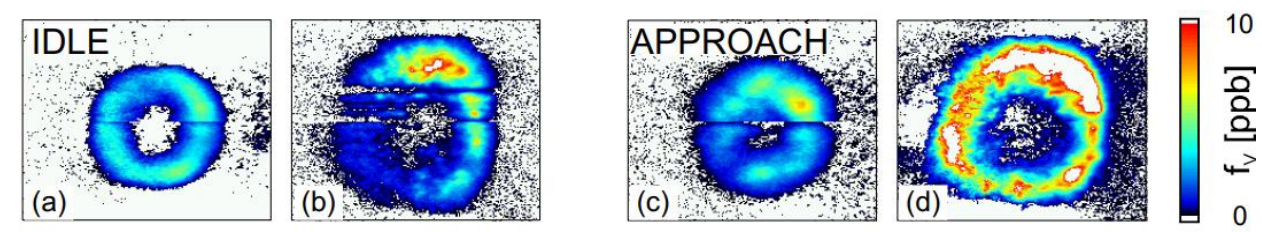

Fig. 10: Soot concentrations in planes parallel to the burner front plate for idle and approach, at $4 \mathrm{~mm}$, (a) and (c), and $13 \mathrm{~mm}$ distance, (b) and (d), respectively.

\section{SUMMARY}

Laser-induced incandescence has successfully been applied to a spray combustor at technical conditions, covering some of the ICAO Landing and Take-off Cycle (LTO) operating points and variations of the main operating parameters. Maximum operating pressure during the tests was 23 bar while this paper describes results between 4 and 20 bar. Interferences from scattered plasma light induced by the laser focus on the combustion chamber surface had to be removed from the images during data analysis. For quantification of LII a stable premixed flame at ambient pressure was employed and LII correlated to a line-of-sight extinction experiment at $1064 \mathrm{~nm}$ while using the same optical setup as in the technical experiment. This approach is known to bias soot 
volume fractions determined for high pressures towards too small values but appeared to be the only feasible, yet inducing only minor error. Soot concentrations determined under the defined technical conditions remained clearly below $1 \mathrm{ppm}$ peak in single shot images and even one order of magnitude lower in averages over 300 instantaneous images using the described calibration. Thus, the studied spray injector showed a very good performance with respect to soot emissions even when keeping in mind the given uncertainties at high pressure. Together with $\mathrm{OH}$ and kerosene PLIF experiments applied to the same combustor [27, 28] a comprehensive data set at highly technical conditions is established that can be used for validation of simulation tools.

\section{ACKNOWLEDGEMENT}

Funding of the work by the European Community under the Sixth Framework Programme, Aeronautics and Space, project TLC - Towards Lean Combustion Contract N ${ }^{\circ}$ AST4-CT-2005012326 is gratefully acknowledged. Additionally, special thanks are expressed for the excellent support of the test campaign by J.J Lecout, E. Paux and E. Landais.

\section{REFERENCES}

[1] H.T. Brocklehurst, J.B. Moss, C.D. Hurley, C.H. Priddin: Proc. RTO AVT Symposium on "Gas Turbine Engine Combustion, Emissions and Alternative Fuels", 1998,

[2] V. Raman, R.O. Fox: Annual Review of Fluid Mechanics 48, 159 (2016)

[3] C. Eberle, P. Gerlinger, K.P. Geigle, M. Aigner: Combustion Science and Technology 190, 1194 (2018)

[4] R.J. Santoro, C.R. Shaddix: Laser-induced incandescence, in: K. Kohse-Höinghaus, J.B. Jeffries (Eds.) Applied Combustion Diagnostics, Taylor \& Francis, New York, 2002, pp. 252

[5] H.A. Michelsen, C. Schulz, G.J. Smallwood, S. Will: Progress in Energy and Combustion Science 51, 2 (2015)

[6] J.A. Pinson, D.L. Mitchell, R.J. Santoro, T.A. Litzinger: SAE Technical Paper 932650, Society of Automotive Engineers, Warrendale, Pa., 1993

[7] G. Wiltafsky, W. Stolz, J. Köhler, C. Espey: SAE Technical Paper 961200, Society of Automotive Engineers, Warrendale, Pa., 1996

[8] J.E. Dec, A.O. zur Loye, D.L. Siebers: SAE Technical Paper 910224, Society of Automotive Engineers, Warrendale, Pa., 1991

[9] L.M. Pickett, D.L. Siebers: Combustion and Flame 138, 114 (2004)

[10] L. de Francqueville, G. Bruneaux, B. Thirouard: SAE International Journal Engines 3, 163 (2010)

[11] K.P. Geigle, R. Hadef, W. Meier: Journal of Engineering for Gas Turbines and Power 136, 021505 (2014)

[12] U. Meier, J. Heinze, E. Magens, M. Schroll, C. Hassa, S. Bake, T. Doerr: Proc. ASME Turbo Expo, 2015, GT2015-43391

[13] K.P. Geigle, M. Köhler, W. O'Loughlin, W. Meier: Proceedings of The Combustion Institute 35, $3373(2015)$

[14] M. Hofmann, W.G. Bessler, C. Schulz, H. Jander: Applied Optics 42, 2052 (2003)

[15] H.A. Michelsen, P.E. Schrader, F. Goulay: Carbon 48, 2175 (2010)

[16] J. Zerbs, K.P. Geigle, O. Lammel, J. Hader, R. Stirn, R. Hadef, W. Meier: Applied Physics B 96, 683 (2009)

[17] R.L. Vander Wal, D.L. Dietrich: Applied Optics 34, 1103 (1995)

[18] O. Lammel, K.P. Geigle, R. Lückerath, W. Meier, M. Aigner: Proc. ASME Turbo Expo, 2007, GT2007-27902

[19] R.L. Vander Wal: Applied Physics B 96, 601 (2009)

[20] G.B. Kim, J.Y. Shim, S.W. Cho, Y.J. Chang, C.H. Jeon: Journal of Mechanical Science and Technology 22, 1154 (2008)

[21] E. Cenker, G. Bruneaux, T. Dreier, C. Schulz: Applied Physics B 119, 745 (2015)

[22] R. Hadef, K.P. Geigle: Unpublished results, 2018 
[23] R. Hadef, K.P. Geigle, W. Meier, M. Aigner: International Journal of Thermal Sciences 49, 1457 (2010)

[24] S.Y. Lee, S.R. Turns, R.J. Santoro: Combustion and Flame 156, 2264 (2009)

[25] M. Köhler, K.P. Geigle, T. Blacha, P. Gerlinger, W. Meier: Combustion and Flame 159, 2620 (2012)

[26] U. Meier, C. Hassa, K.P. Geigle, O. Lammel, P. Kutne: Proc. 1st CEAS European Air and Space Conference, 2007, Paper 233

[27] F. Grisch, M. Orain, B. Rossow, E. Jourdanneau, C. Guin: Proc. 44th AIAA/ASME/SAE/ ASEE Joint Propulsion Conference \& Exhibit, 2008, AIAA 2008-4868

[28] M. Orain, F. Grisch, E. Jourdanneau, B. Rossow, C. Guin, B. Tretout: Comptes Rendus Mecanique 337, 373 (2009)

[29] F. Dupoirieux, N. Bertier, C. Guin, K.P. Geigle, C. Eberle, P. Gerlinger: Aerospace Lab Journal $11-07,1(2016)$ 